\begin{tabular}{|c|c|}
\hline ULNAL INSL & $\begin{array}{l}\text { Volume } 3 \text { Nomor. 1, April } 2018 \\
\text { P-ISSN : 2541-1179, E-ISSN : 2581-1711 } \\
\text { Ojs :http://journal.uin-alauddin.ac.id/index.php/instek/index }\end{array}$ \\
\hline INFORMATIKASANSOANTEXNOLOGI & Email : instek@uin-alauddin.ac.id \\
\hline
\end{tabular}

\title{
PERANCANGAN SOFTWARE IDS SNORT UNTUK PENDETEKSIAN SERANGAN INTERRUPTION (Netcut) PADA JARINGAN WIRELESS
}

\author{
Muhammad Akbar \\ akbar.stmikhdy@gmail.com \\ Sistem Komputer STMIK Handayani Makassar
}

\begin{abstract}
Abstrak
Berkembangnya penggunaan internet di kalangan masyarakat, semakin membuat keamanan jaringan lebih rentan terhadap gangguan. Tujuan dari penelitian ini adalah merancang software IDS jenis SNORT yang berfungsi untuk melakukan pendeteksian serangan interruption, dimana hal ini adalah serangan terhadap jaringan $\mathrm{WiFi}$ atau wireless. Metode yang digunakan adalah perancangan software IDS yang bekerja dengan memantau berkas-berkas sistem operasi, yakni dengan cara melihat apakah ada percobaan untuk merubah berkas-berkas sistem operasi, utamanya berkasi file log. Hasil dari penelitian ini adalah software IDS yang dapat diinstal langsung ke komputer, baik dengan sistem operasi Linux maupun Windows, sehingga serangan dengan teknik interruption dapat dideteksi.
\end{abstract}

Kata kunci : IDS, SNORT, interruption, software, WiFi

\section{PENDAHULUAN}

Pada era global ini, keamanan sistem komputer berbasis jaringan harus sangat diperhatikan, karena jaringan komputer yang sifatnya publik dan global pada dasarnya tidak aman. Pada saat data terkirim dari suatu terminal asal menuju ke terminal tujuan dalam Internet, data itu akan melewati sejumlah terminal yang lain yang berarti akan memberi kesempatan pada user jaringan yang lain untuk menyadap atau mengubah data tersebut. Khususnya pada jaringan yang menggunakan media WiFI atau Wireless untuk terhubung dengan internet. Penggunaan jaringan wireless ini dapat dijumpai pada banyak tempat, seperti menjamurnya warkop dengan hotspot, universitas, perusahaan, sampai 


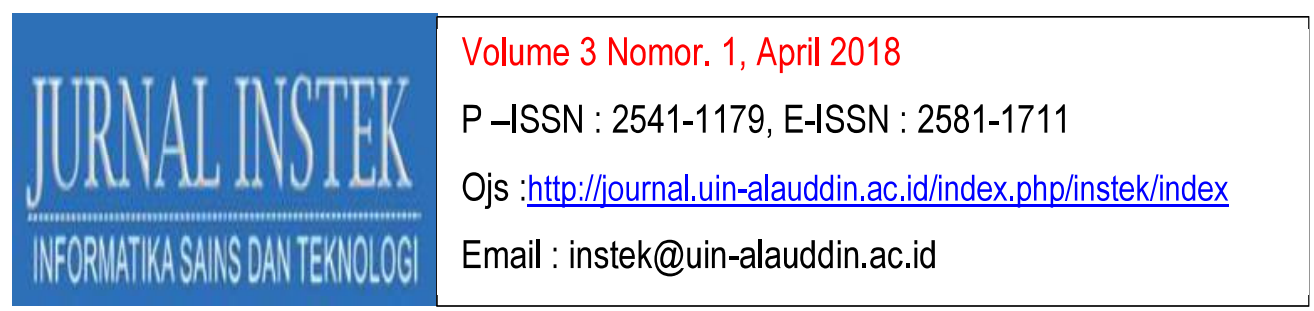

penggunaan untuk rumahan pun telah banyak menggunakan sistem ini. Karena pada realitasnya, internet memang sudah menjadi kebutuhan utama bagi kalangan masyarakat. Untuk itu, pengamanan jaringan harus menjadi pekerjaan rumah yang harus dikerjakan oleh pakar keamanan jaringan atau pelaku-pelaku IT.

Serangan dengan metode interruption adalah serangan yang banyak dijumpai pada kasus-kasus keamanan jaringan. Interruption adalah ancaman terhadap availibility (ketersediaan) dimana data dan informasi yang berada dalam sistem komputer dirusak atau dibuang sehingga menjadi tidak ada dan tidak berguna. Contoh dari serangan ini adalah pengrusakan hardware (harddisk dan lain sebagainya), jalur komunikasi baik kabel maupun nirkabel dipotong.

Salah satu aplikasi yang marak digunakan untuk serangan dengan metode interruption adalah netcut. Netcut adalah aplikasi yang mempunyai fungsi untuk menguasai suatu jaringan wifi dalam hotspot, dan fungsi lain yaitu sebagai pemotong akses internet public maupun private yang terdapat pada jaringan LAN, wifi dan hotspot. Netcut juga dapat memotong sambungan koneksi internet suatu client yang saling berhubungan dalam satu jaringan.

\section{METODE PENELITIAN}

\subsection{Interruption}

Interruption adalah salah satu serangan yang berhubungan kepada availibility, dimana serangan ini dapat merusak hardware, software, data dan juga line komunikasi yang terdapat di dalam suatu sistem komputer yang terhubung ke jaringan. Untuk hardware, peralatan dapat dirusak dengan cara langsung (dicuri atau dirampok), ataupun dirusak menggunakan serangan komputer dalam jaringan. Untuk software dan data, dapat dilakukan dengan cara dihapus, sedangkan untuk line komunikasi, kabel dapat dirusak atau diputus, atau dengan menggunaakn serangan pada jaringan komputer. Pada jaringan wireless untuk line komunikasi dapat dilakukan pemotongan jalur komunikasi dengan menggunakan aplikasi netcut yang akan dibahas lebih lanjut pada penelitian ini. 
Volume 3 Nomor. 1, April 2018

P-ISSN : 2541-1179, E-ISSN : 2581-1711

Ojs :http://journal.uin-alauddin.ac.id/index.php/instek/index

NEORUTIKA SAIS SANTEXNODOG

Email : instek@uin-alauddin.ac.id

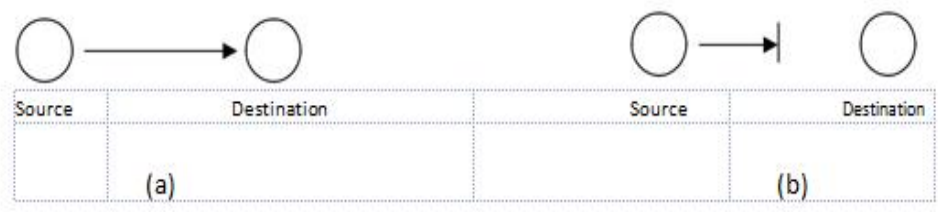

Gambar 1. (a) Jaringan normal (b) jaringan dengan interruption

\section{Netcut}

Netcut atau Network Cut merupakan salah satu aplikasi jenis interruption yang belakangan ini banyak digunakan oleh para pelaku serangan pada jaringan komputer. Netcut adalah aplikasi under windows yang berfungsi untuk melakukan cut (pemotongan) terhadap akses jaringan wireless. Jika seseorang berada dalam jaringan wireless yang terhubung ke jaringan internet, penguna tersebut dapat memutuskan koneksi wireless client lain yang juga dalam satu jaringan, sehingga client yang lain tidak dapat terhubung ke jaringan. Alasan penggunaan netcut biasanya agar pelaku pengguna netcut dapat memanfaatkan seluruh fasilitas jaringan internet yang ada, seperti bandwidth, karena dalam satu jaringan, hanya terdapat satu user, sedangkan user yang lain aksesnya di cut.

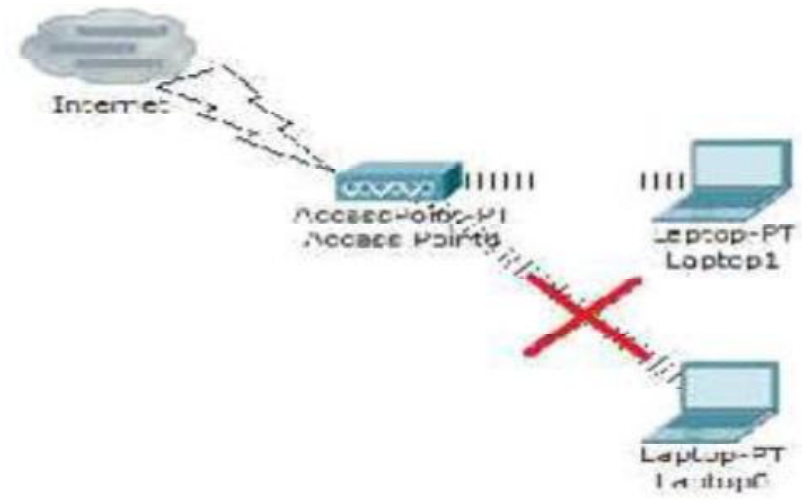

Gambar 2. Skema jaringan penggunaan netcut 
Volume 3 Nomor. 1, April 2018

P-ISSN : 2541-1179, E-ISSN : 2581-1711

Ojs :http://journal.uin-alauddin.ac.id/index.php/instek/index

NFPRUATIKASANSOAN EENOLOOG

Email : instek@uin-alauddin.ac.id

\subsection{Bentuk Ekperimen}

Seperti yang telah disampaikan sebelumnya, untuk software IDS disini dibuat pada sistem operasi Linux Slackware 13. Eksperimen dilakukan dengan menginstallkan software IDS pada sistem operasi Linux, dimana terhubung dengan jaringan internet melalui media wireless. Dalam jaringan tersebut juga terdapat 3 buah user, dimana user 1 akan melakukan akses internet secara normal, user 2 adalah user yang akses internetnya akan di cut, dan user 3 yang menjadi pelaku penyerangan interruption (netcut).

Spesifikasi untuk server IDS dan client sebagai berikut :

1. Server

Sistem Operasi : Slackware 13

Prosesor : : Core 2 Duo

Ram : 3 GB DDR 2

Harddisk : $\quad$ :320 GB

LAN Card : $1 \mathrm{Gbps}$

2. Client

Sistem Operasi : Windows 7

Prosesor : : AMD Athlon Dual Core

Ram $\quad: 1$ GB DDR 2

Harddisk $\quad: 250 \mathrm{~GB}$

LAN Card : $1 \mathrm{Gbps}$

Dalam IDS (Intrusion Detection System) berbentuk SNORT, terdapat beberapa komponen yang biasa digunakan, seperti Snort (Engine dan Rules), BASE (Basic Analysis and Security Engine) dan IPtables (Firewall). Konfigurasi snort merupakan langkah awal dalam penelitian ini. Snort dapat diinstal secara free karena merupakan aplikasi open source yang secara default telah terinstal pada linux Slackware 13. Setelah terinstal, rules yang ingin digunakan diaktifkan, 


\begin{tabular}{|c|c|}
\hline SII & $\begin{array}{l}\text { Volume } 3 \text { Nomor. 1, April } 2018 \\
\text { P-ISSN : 2541-1179, E-ISSN : 2581-1711 } \\
\text { Ojs :http://journal.uin-alauddin.ac.id/index.php/instek/index }\end{array}$ \\
\hline NEFORMATIKASAMSOANTEXNOLOCL & Email : instek@uin-alauddin.ac.id \\
\hline
\end{tabular}

semisal rules backdoor, dns, dos, dan rules-rules lainnya. Selebihnya paket pendukung lainnya dapat diinstal secara online melalui repository online.

Tahap selanjutnya yakni pembuatan database menggunakan MySql dengan komunikasi Apache dan PHP untuk web services. Iptables pada sistem ini berfungsi sebagai firewall. Konfigurasi firewall dapat dilihat pada gambar berikut

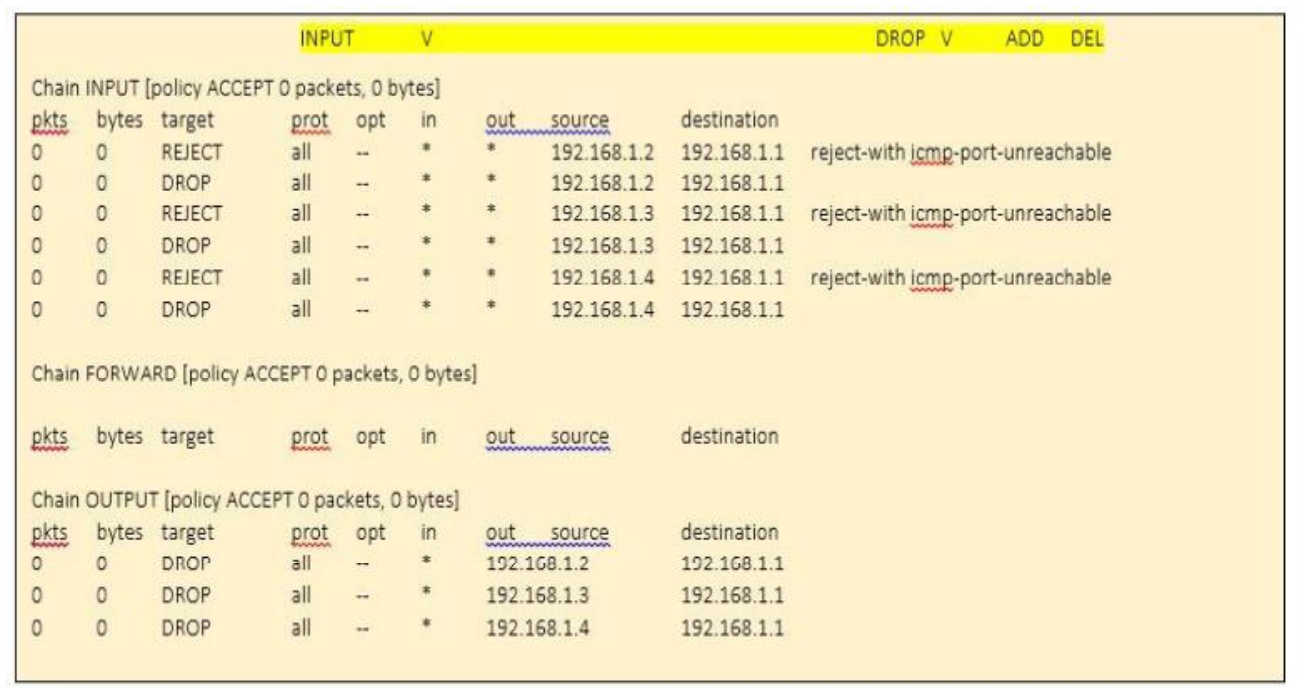

Gambar 3.Konfigurasi Firewall

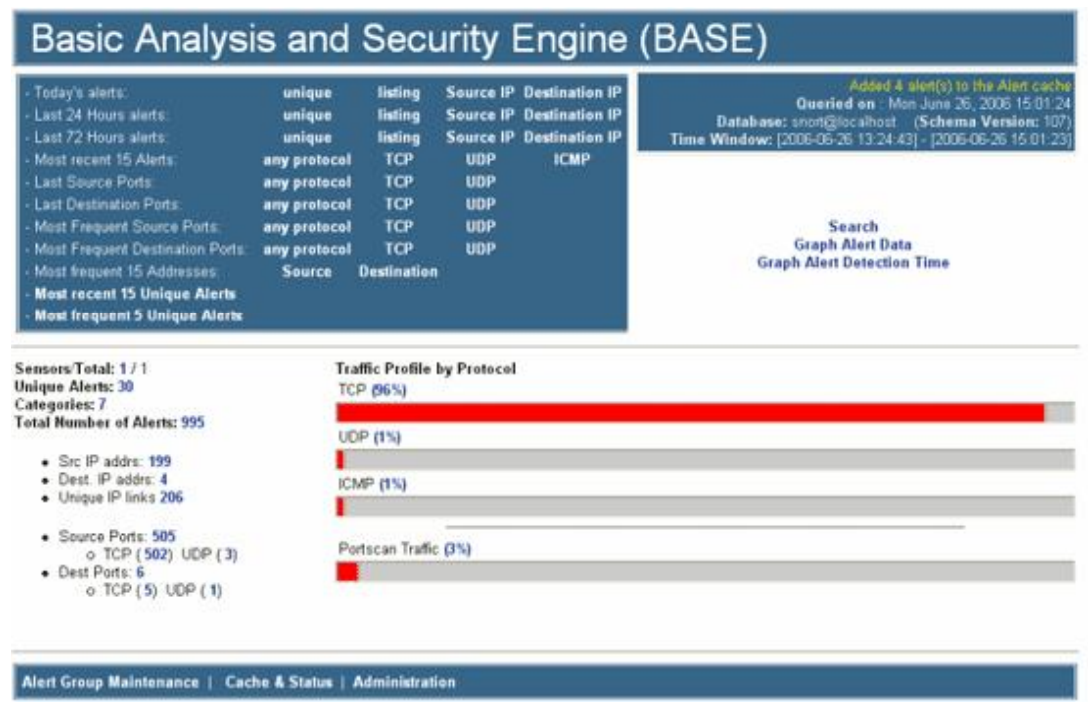

Gambar 4.Tampilan BASE (Basic Analysis and Security Engine) 
Volume 3 Nomor. 1, April 2018

P-ISSN : 2541-1179, E-ISSN : 2581-1711

Ojs :http://journal.uin-alauddin.ac.id/index.php/instek/index

Email : instek@uin-alauddin.ac.id

Secara arsitektur komunikasi, dapat digambarkan dalam bentuk flowchart sistem sebagai berikut :

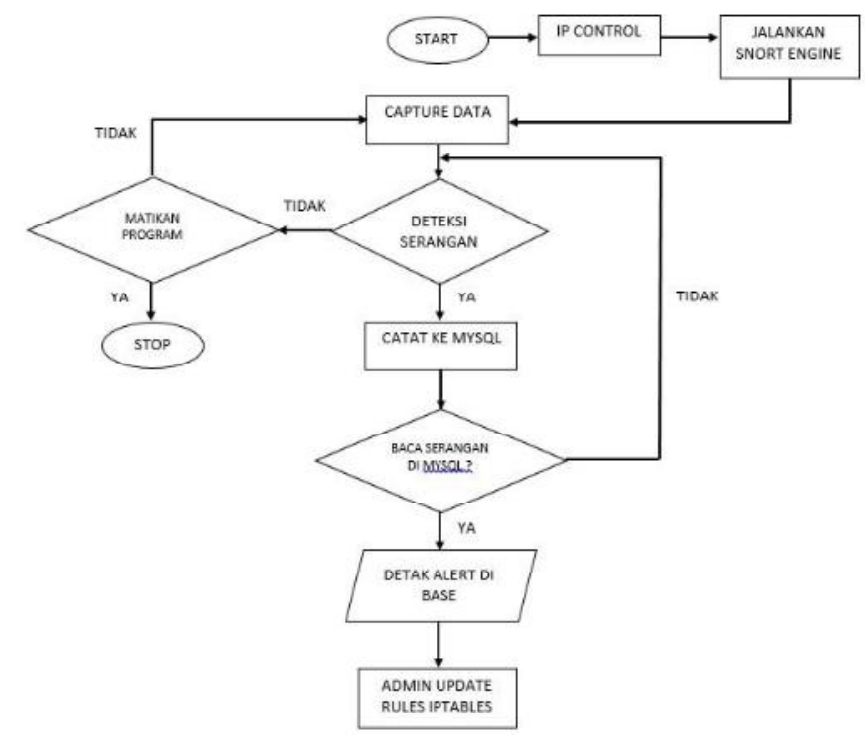

Gambar 5. Flowchart sistem IDS (SNORT)

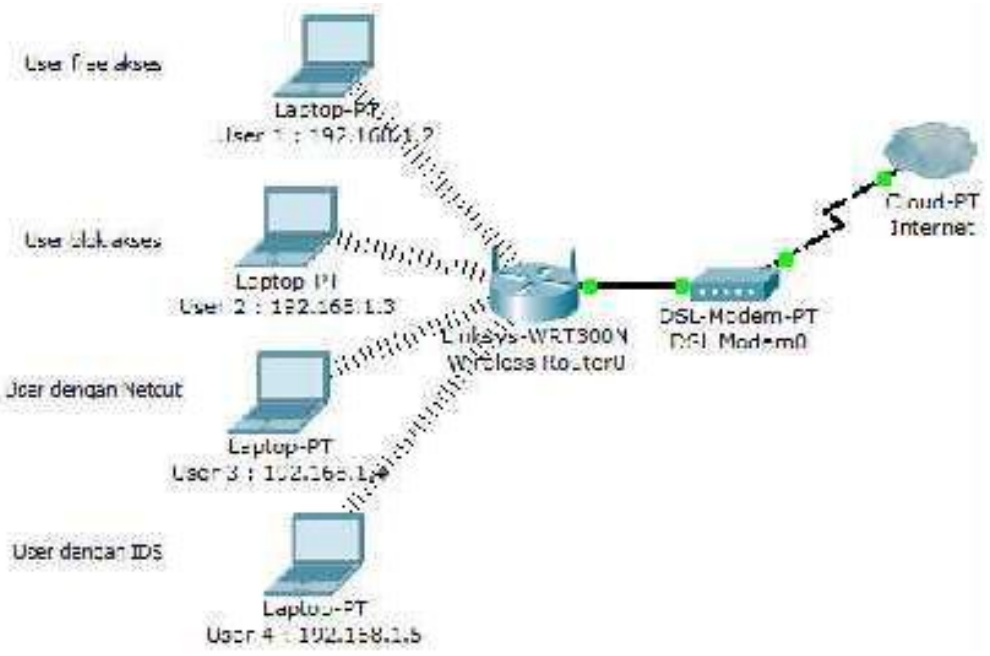

Gambar 6. Skema jaringan eksperimen 


\begin{tabular}{|c|c|}
\hline$\sqrt{5} \int^{1}$ & $\begin{array}{l}\text { Volume } 3 \text { Nomor. 1, April } 2018 \\
\text { P -ISSN : 2541-1179, E-ISSN : 2581-1711 } \\
\text { Ojs :http://journal.uin-alauddin.ac.id/index.php/instek/index }\end{array}$ \\
\hline NFEORMATIKASANSOANTEXNOLOGI & Email : instek@uin-alauddin.ac.id \\
\hline
\end{tabular}

\section{HASIL DAN PEMBAHASAN}

\subsection{Percobaan Serangan Interruption}

Berdasarkan dari eksperimen yang telah dilakukan, hasilnya menunjukkan bahwa, user 2 dengan IP address 192.168.1.3 telah berhasil diserang oleh user 3 dengan IP address 192.168.1.4 menggunakan aplikasi atau tools netcut. Hal ini mengakibatkan user 2 tidak dapat mengakses internet. Karena akses internetnya telah di cut oleh user 3. Hal tersebut dapat terdeteksi pada aplikasi web BASE, dimana terlihat paket ICMP yang mencapai angka 90\%, karena pada dasarnya serangan Netcut menggunakan protocol ICMP dalam pengoperasiannya.

\section{Basic Analysis and Security Engine (BASE)}
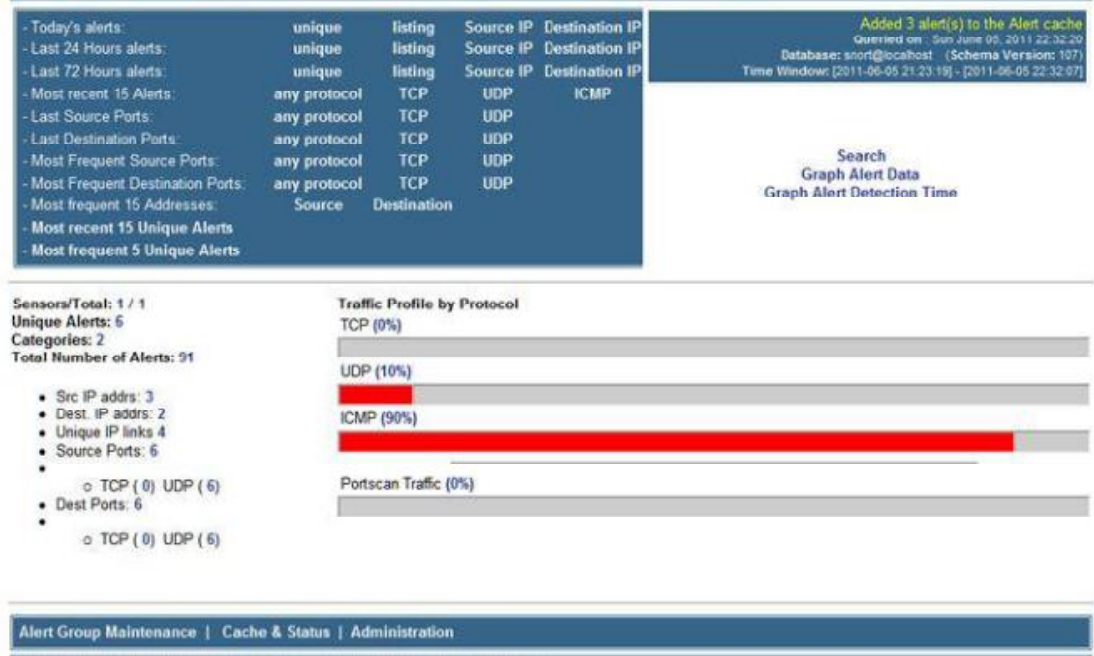

Gambar 7. Deteksi Serangan ICMP Netcut

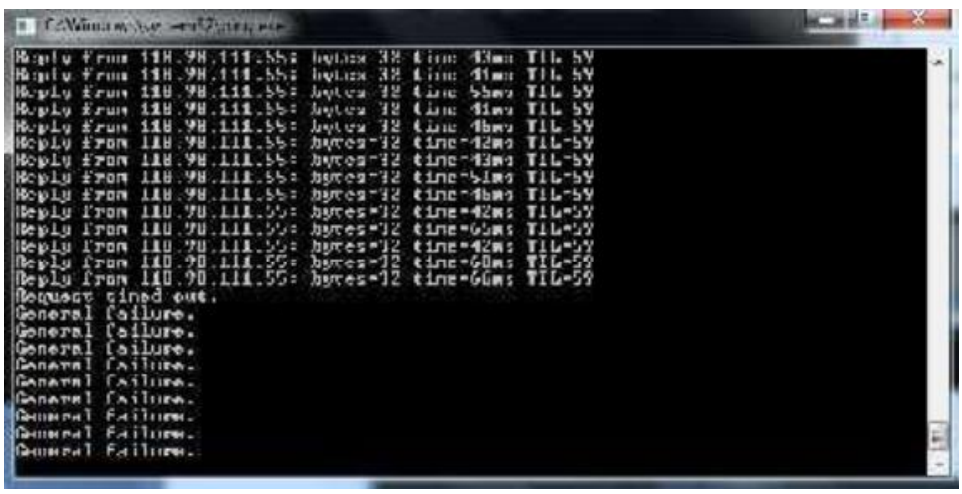

Gambar 8. Tampilan Ping Client Setelah Terserang Netcut 


\begin{tabular}{|c|c|}
\hline Wlill & $\begin{array}{l}\text { Volume } 3 \text { Nomor. 1, April } 2018 \\
\text { P-ISSN : 2541-1179, E-ISSN : 2581-1711 } \\
\text { Ojs :http://journal.uin-alauddin.ac.id/index.php/instek/index }\end{array}$ \\
\hline NNERMATIKASAMSOANTEENOLOCL & Email : instek@uin-alauddin.ac.id \\
\hline
\end{tabular}

Pada eksperimen yang dilakukan menggunakan 4 buah user dengan range IP Address 192.168.1.2 - 192.168.1.5. Untuk komunikasi wireless menggunakan access point Linksys dengan kecepatan $54 \mathrm{Mbps}$ dan untuk internet menggunakan koneksi Telkom Speedy dengan kecepatan 1MB. User 1 sampai dengan user 3 menggunakan sistem operasi Windows 7 Ultimate 32 bit.

Setelah user 3 melakukan serangan ke user 2, maka program IDS yang terdapat pada user 4 akan secara otomatis mendeteksi serangan tersebut. Sehingga dapat segera diketahui pelaku serangan interruption tersebut dari informasi tampilan program IDS. Informasi yang ditampilkan oleh program IDS adalah berupa IP addres dari pelaku serangan, seperti terlihat pada gambar di bawah :

\section{Displaying alerts $1-8$ of 8 total}

\begin{tabular}{|c|c|c|c|c|c|}
\hline \multicolumn{2}{|l|}{ |D 〈Signature〉 } & \multirow{2}{*}{$\begin{array}{l}\text { 〈Timestamp〉 } \\
2016-10-2620 \cdot 36: 40\end{array}$} & \multicolumn{3}{|c|}{ 〈Source Address〉〈Dest. Address〉 SLlaver 4 Proto } \\
\hline$\# 0-(3-21)$ [snort $]$ & ICMP Destination Unreachable (Undefined Code/NetCUT) & & 192.168.1.2. & 192.168 .13 & ICMP \\
\hline$\# 1-|3-22|[$ [noort] & ICMP Destination Unreachable (Undefined Code/NetCUT) & $2016-10-2620: 36 \cdot 40$ & 192.168.1.2 & 192.168 .13 & ICMP \\
\hline$\# 2-(3-23) \mid$ snort] & ICMP Destination Unreachable (Port Unreach/NetCuT) & $2016-10-2620.36 \cdot 39$ & 192.168.1.2 & 192.168 .13 & ICMP \\
\hline$\# 3-13-24)[$ [noort] & ICMP Destination Unreachable (Port Unreach/NetCuT) & $2016-10-2620 \cdot 36 \cdot 39$ & 192.168.1.2 & 192.168 .13 & ICMP \\
\hline$\# 4-3-18 \mid[$ snort] & ICMP Destination Unreachable (Undefined Code/NetCUT) & $2016-10-2620 \cdot 36 \cdot 38$ & 192.168.1.2 & 192.168 .13 & ICMP \\
\hline \#5-(3-19)|[snort] & ICMP Destination Unreachable (Port Unreach/NetCuT) & $2016-10-2620 \cdot 36 \cdot 38$ & 192.168.1.2 & 192.168 .13 & ICMP \\
\hline$\# 6-33-20 \mid[$ snort] & ICMP Destination Unreachable (Port Unreach/NetCuT) & $2016-10-2620 \cdot 36 \cdot 37$ & 192.168.1.2 & 192.168 .13 & ICMP \\
\hline$\# 7-\mid 3-17) \mid[$ snort $]$ & ICMP Destination Unreachable (Undefined Code/NetCUT) & $2016-10-2620: 36: 37$ & 192.168.1.2 & 192.168 .13 & ICMP \\
\hline
\end{tabular}

ACTION

Gambar 9. Tampilan Notifikasi Alert Pada BASE

\section{IV.PENUTUP}

\subsection{KESIMPULAN}

Dari penelitian yang telah dilakukan, dapat disimpulkan bahwa program IDS yang digunakan pada penelitian ini hanya dapat mendeteksi serangan interruption (Netcut) saja, serangan jenis lain belum dapat dideteksi. Program IDS dapat mendeteksi dengan baik serangan netcut yang terjadi pada jaringan. Program netcut yang dijalankan dapat melakukan pemotongan jalur koneksi wifi pada user yang lain. Hal tersebut dapat dilakukan secara simultan ke semua user yang ada pada jaringan..Program IDS hanya dapat mendeteksi serangan, namun tidak dapat melakukan pengamanan, oleh karena itu IDS dapat disandingkan 
Volume 3 Nomor. 1, April 2018

P-ISSN : 2541-1179, E-ISSN : 2581-1711

Ojs :http://journal.uin-alauddin.ac.id/index.php/instek/index

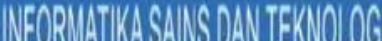

Email : instek@uin-alauddin.ac.id

dengan program pengamanan netcut yang lain seperti anti netcut, netcut defender, dan lain-lain. Jaringan yang digunakan akan lebih aman jika menggunakan keamanan tambahan seperti mikrotik, karena berdasarkan penelitian serangan netcut tidak dapat berfungsi pada jaringan yang terdapat mikrotik di dalamnya.

\section{DAFTAR PUSTAKA}

http://ezine.omega.or.id/1/konsep-keamanan\&kerahasiaan-data-1.txt diakses pada 28-11-2014 pukul 09.01

http://www.it-newbie.com/2014/09/cara-mudah-menggunakan-netcut-padawifi.html diakses pada 28-11-2014 pukul 09.06

https://www.facebook.com/permalink.php?story_fbid=225483790977295\&id= 186378531554488 diakses pada 04-12-2014 pukul 14.13

http://pacarita.com/pengertian-wireless-dan-cara-kerja-wireless.html diakses pada $04-12-2014$ pukul 14.17

indra sufian. Langkah-langkah sederhana untuk mengamankan handphone dan tablet anda. magcover. 2012 